\title{
DESAIN LANSKAP EKORIPARIAN BABAKAN PASAR, BOGOR
}

Ecoriparian Landscape Design of

Babakan Pasar, Bogor

\section{Daisy Radnawati}

Fakultas Teknik Sipil dan Perencanaan (FTSP), Institut Sains dan Teknologi Nasional

Email: daisyradnawati@gmail.com

\section{Desy Fatmala Makhmud}

Fakultas Teknik Sipil dan Perencanaan (FTSP), Institut Sains dan Teknologi

Nasional

Email: desyfatmala04@gmail.com

\section{ABSTRACT}

Environmental management, especially the water resources sector in Indonesia is experiencing greater pressure from the use of environmental resources compared to efforts to improve environmental quality. The Ministry of Environment and Forestry (KLHK) has collaborated with society through communities to combine the concept of riparian planning with efforts reducing the pollution load from domestic waste and making the place a center for education and environmental conservation, this concept is called ecoriparian. One of the locations planned for ecoriparian planning is located in the Ciliwung Watershed, located in Babakan Pasar Village, Central Bogor District, Bogor City, West Java. This area is located in a densely populated settlement with a strategic location and is thick with pluralistic values. The approach used in this research refers to Gold's (1980) design process, this stage starts from preparation, inventory, analysis, synthesis, concept and design. The results of this research are expressed in the form of a concept and visual design of the Babakan Pasar Ecoriparian Park which develops potentials on the site, the landscape design uses the Chinese and Sundanese cultural approach as outlined in the spatial concept of elemental form and color selection. In this research, is expected the exsistence of this ecoriparian park can improve the quality of the Ciliwung River, change the mindset of the community regarding river preservation and add to the aesthetic value of an area.

Keywords: Environmental Management, Riparian Planning, Watershed.

\section{PENDAHULUAN}

Sungai merupakan salah satu sumber daya air yang memiliki fungsi sangat penting bagi kelangsungan dan kesejahteraan hidup manusia dan makhluk hidup lainnya, sehingga merupakan modal dasar dan faktor utama dalam pembangunan. Sungai tidak hanya dipandang sebagi drainase alami, sungai dapat dilihat sebagai aset vital, aset lanskap, dan aset sosial budaya, berdasarkan Laporan Indeks Kualitas Lingkungan Hidup (IKLH) menunjukkan bahwa nilai Indeks Kualitas Air (IKA) mengalami penurunan dibandingkan dengan tahun sebelumnya, pada tahun 2018 IKA Nasional mencapai 72,77 kemudian turun menjadi 52,62 pada tahun 2019 (KLHK, 2019). Hal ini menunjukkan pengelolaan lingkungan terutama bidang sumber daya air di Indonesia sedang mengalami tekanan yang lebih besar dari pemanfaatan sumber daya lingkungan dibandingkan dengan upaya perbaikan kualitas lingkungan hidup, oleh karena itu dirasa perlu untuk melakukan pengelolaan dan pengendalian sungai secara benar dan berkelanjutan untuk menjaga keseimbangan ekologis.

Kementerian Lingkungan Hidup dan Kehutanan (KLHK) telah bekerjasama dengan masyarakat melalui komunitaskomunitas. Dalam hal ini telah dilakukan penyusunan konsep perencanaan riparian dengan upaya penurunan beban pencemaran dari limbah domestik, dan menjadikan tempat tersebut sebagai pusat edukasi dan konservasi lingkungan, konsep ini disebut ekoriparian.

Salah satu lokasi yang direncanakan untuk dilakukan perencanaan ekoriparian berlokasi di Sungai Ciliwung. Sungai ini mengalir melalui tengah kota Jakarta dan melintasi banyak permukiman padat penduduk, selain sering menyebabkan banjir, kondisi Sungai Ciliwung juga tercemar berat baik dari limbah domestik maupun nondomestik (Yudo dan Said, 2018). Kerusakan lanskap Sungai Ciliwung sebenarnya akibat dari dampak kehidupan manusia yang hidup di sepanjang sungai tersebut, serta kebijakan-kebijakan yang tidak konsisten dan dianggap tidak pro lingkungan disinyalir menjadi penyebab degradasi lanskap Sungai Ciliwung. Peningkatan perubahan tata guna lahan pada bagian hulu, tengah hingga hilir tidak dapat dihindari, sehingga langsung ataupun tak langsung menyebabkan kondisi ekologis Sungai Ciliwung juga akan semakin merosot (Soewandita dan Sudiana, 2010).

Area yang akan direncanakan menjadi taman Ekoriparian Sungai Ciliwung berlokasi di sempadan sungai Babakan Pasar, Kota Bogor. Area ini berada di permukiman padat penduduk dengan lokasi yang strategis dan kental akan nilai pluralisme. Menyadari potensi-potensi dan permasalahan yang dapat dikembangkan, maka di area ini akan dilakukan penataan lanskap riparian melalui proses analisis dan konsep desain yang sesuai dengan kondisi lingkungan sekitar, dalam penelitian ini diharapkan keberadaan ekoriparian Babakan Pasar dapat memperbaiki kualitas Sungai Ciliwung, mengubah pola pikir masyarakat mengenai kelestarian sungai dan menambah nilai estetis suatu kawasan.

\section{METODE}

\section{Lokasi dan Waktu Penelitian}

Kegiatan penelitian dilakukan di sempadan Sungai Ciliwung yang berada di Kelurahan Babakan Pasar, Kecamatan Bogor Tengah, Kota Bogor, Jawa Barat. Area yang akan direncakan menjadi taman ekoriparian seluas $0.4 \mathrm{Ha}$ (Gambar 1). Penelitian dilakukan selama 2 bulan, dimulai dari Desember 2019 hingga Januari 2020.

\section{Alat dan Bahan}

Alat dan bahan yang digunakan pada penelitian ini terdiri dari GPS Garmin 78S untuk menentukan titik koordinat tapak pada saat survei, kamera digital untuk dokumentasi 

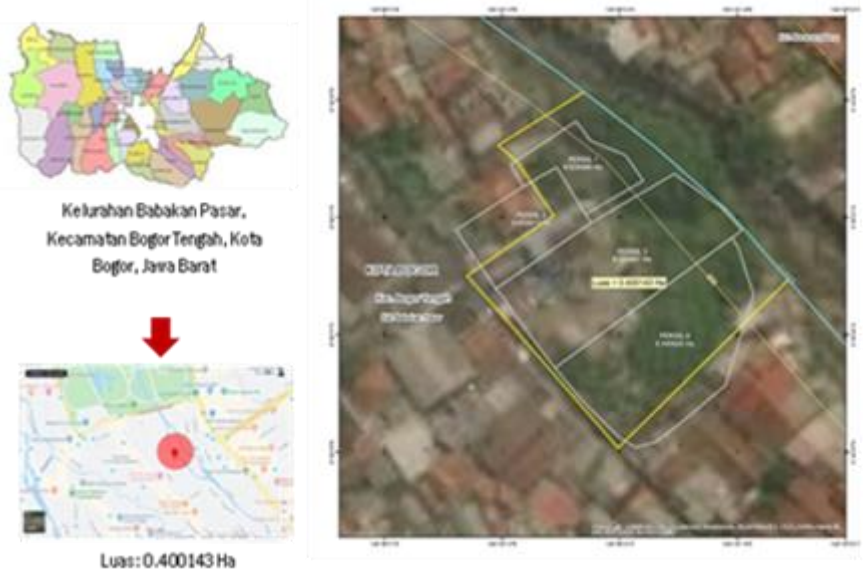

Gambar 1. Lokasi Babakan Pasar

kondisi tapak, meteran dan alat tulis. Aplikasi komputer yang digunakan adalah software ArcGIS 10.1 untuk mendeliniasi peta berdasarkan hasil koordinat yang telah didapatkan dari GPS, kemudian software Autocad 2017 untuk mendesain siteplan dalam bentuk dua dimensi, Sketchup 2017 untuk menginterpretasikan gambar dalam bentuk tiga dimensi dan Lumion 8 untuk proses rendering.

\section{Metode Penelitian}

Penelitian ini menggunakan metode deskriptif dan spasial, data dikumpulkan melalui observasi langsung di area sempadan Sungai Babakan Pasar yang akan dijadikan sebagai lokasi perencanaan ekoriparian. Pendekatan yang digunakan dalam penelitian ini mengacu pada proses perancangan Gold (1980). Menurut Gold, dalam melakukan perancangan dibutuhkan inventarisasi data, analisis, dan sintesis yang digunakan sebagai acuan untuk menghasilkan sebuah rancangan atau desain.

Berikut penjabaran metode yang digunakan dalam penelitian ini:

1) Persiapan, pada tahap ini dilakukan penentuan lokasi, tujuan, potensi dan permasalahan serta dasar informasi yang dibutuhkan.

2) Inventarisasi, merupakan tahap untuk mengumpulkan data eksisting di kawasan Babakan Pasar, jenis data yang dikumpulkan adalah data primer dan sekunder. Data primer diperoleh melalui survei langsung, berupa data fisik, biofisik, dan sosial. Data sekunder adalah data berupa data tambahan yang diperoleh dari studi pustaka.

3) Analisis, hasil identifikasi data yang diperoleh baik data primer maupun sekunder kemudian dijabarkan secara deskriptif untuk menentukan konsep perencanaan yang sesuai di lokasi penelitian. Analisis spasial dilakukan dalam mengolah data fisik, biofisik dan sosial untuk menemukan dan menggambarkan pola ruang secara spasial.

4) Sintesis, hasil analisis kemudian disintesis untuk mendapatkan pemecahan masalah yang akan menghasilkan konsep zonasi serta konsep perancangan yang selanjutnya akan dikembangkan pada tahap desain.

5) Konsep, hasil sintesis digunakan sebagai dasar pengembangan konsep. Terdiri dari konsep dasar, konsep desain, konsep bentuk, konsep ruang, konsep visual, konsep sirkulasi dan konsep vegetasi, hasil

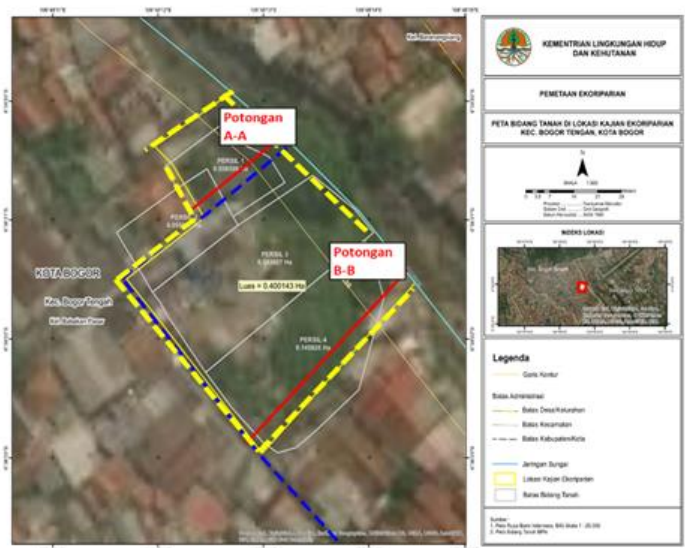

Gambar 2. Deskripsi Tapak Ekoriparian Babakan Pasar

akhir dari tahap ini penggabungan konsep yang dibuat dalam bentuk block plan.

6) Desain, block plan (rencana blok) selanjutnya dikembangkan menjadi site plan (rencana tapak), pada tahap ini rencana tapak yang telah di desain akan divisualisasikan dalam bentuk dua dimensi yang memperlihatkan peletakan fasilitas softscape maupun hardscape. Kemudian gambar divisualisasikan dalam bentuk tiga dimensi yang menghasilkan gambar tampak secara keseluruhan (bird view), gambar perspektif, dan gambar potongan.

\section{HASIL DAN PEMBAHASAN}

\section{Deskripsi Tapak}

Lokasi tapak berada di sempadan Sungai Ciliwung, Babakan Pasar (Gambar 2). Pencemaran domestik berasal dari aktivitas rumah tangga (permukiman) yang masuk langsung ke Sungai Ciliwung. Tapak terpilih merupakan bekas bangunan pabrik kulit, di dalam tapak terdapat bunker dan beberapa fasilitas bekas bangunan pabrik kulit yang saat ini sudah tidak digunakan lagi. Tapak kini aktif digunakan sebagai area pembibitan (nursery), lahan parkir dan lokasi latihan barongsai. Potongan eksisting A-A dan B-B dapat dilihat pada Gambar 3.

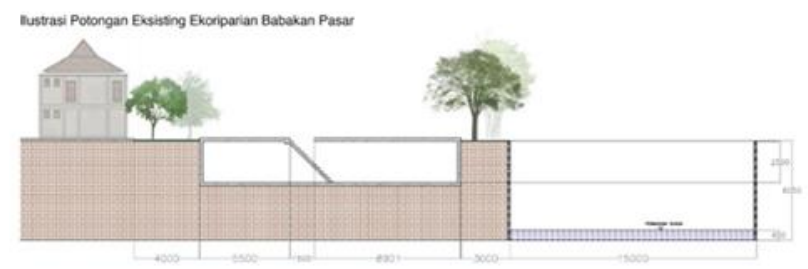

Potongan A-A

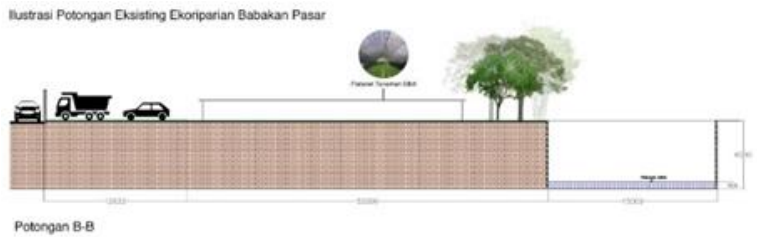

Gambar 3. Potongan Tapak Ekoriparian Babakan Pasar

\section{Analisis Tapak}

\section{A. Tautan Lingkungan, Akses Masuk dan Sirkulasi.}

Kawasan Sungai Ciliwung Babakan Pasar berbatasan dengan pemukiman warga dan kantor kelurahan. Kondisi 

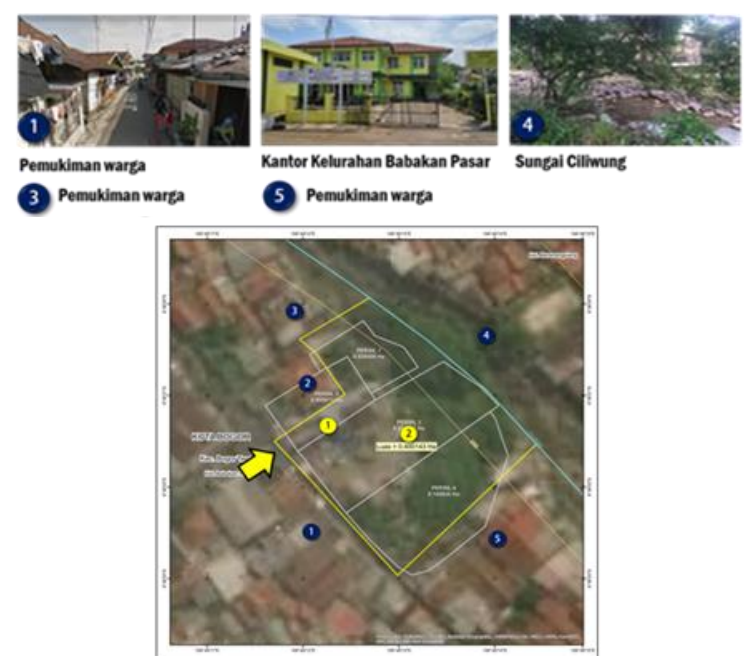

Gambar 4. Tautan Lingkungan pada Tapak

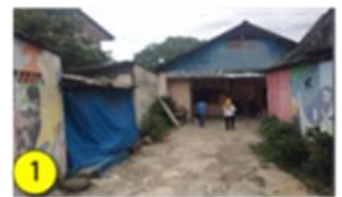

Pintu masuk utama

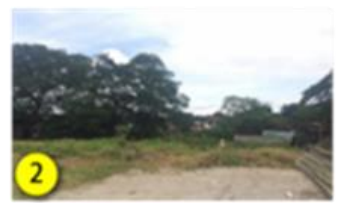

Tidak ada sirkulasi yang jelas Dalam tapak

Gambar 5. Akses Masuk dan Sirkulasi Pada Tapak

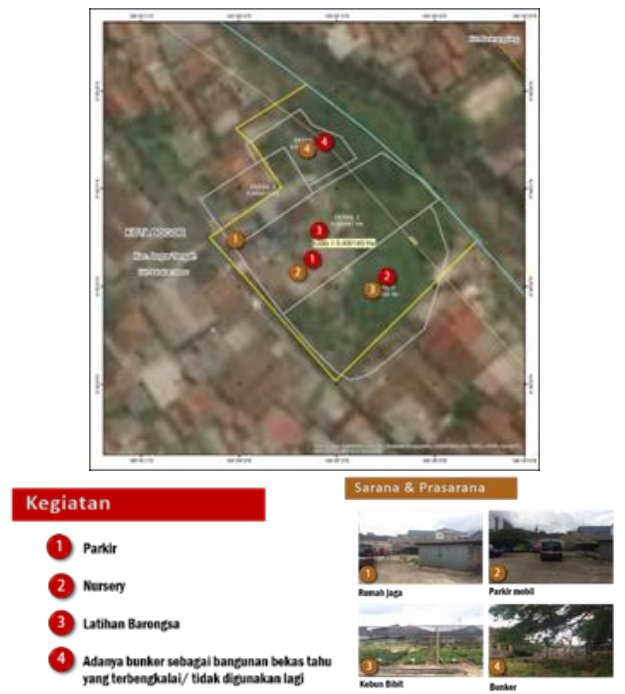

Gambar 6. Sarana dan Prasarana pada Tapak
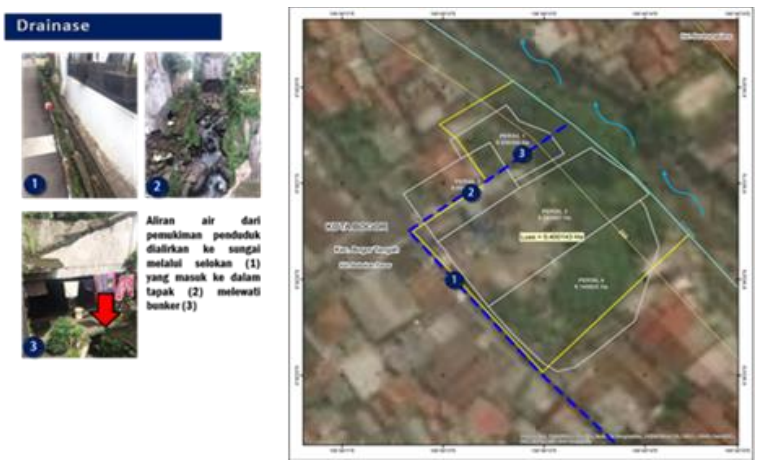

Gambar 7. Drainase pada Tapak

lingkungan tapak sendiri terdapat pencemaran limbah domestik yang berasal dari permukiman padat penduduk di sekitar tapak (Gambar 4).
Akses masuk ke dalam tapak cukup sulit karena harus melewati rumah warga, jalur sirkulasi di dalam tapak belum jelas, hanya terdapat plaza dari perkerasan beton yang cukup luas (Gambar 5). Solusi untuk akses masuk ke dalam tapak yaitu memindahkannya ke area yang lebih terbuka dan berhubungan langsung dengan jalur sirkulasi luar tapak. Selain itu, diperlukannya penataan jalur sirkulasi sehingga aktivitas di dalam tapak lebih teratur.

\section{B. Sarana dan Prasarana}

Sarana dan prasarana yang terdapat di tapak yaitu rumah jaga di area depan yang berfungsi untuk menjaga keamanan kawasan, lahan parkir yang cukup luas berupa perkerasan beton untuk mobil maupun motor, kebun bibit (nursery) tanaman kayu yang dikelola oleh masyarakat sekitar, dan bunker bekas pabrik kulit yang sudah tidak digunakan (Gambar 6). Untuk menjadikan tapak sebagai taman ekoriparian dibutuhkan penataan dan penambahan fasilitas, dibutuhkan pula pengelolaan tapak yang baik dan teratur.

\section{Drainase}

Terdapat saluran pembuangan limbah rumah tangga pada tapak yang secara langsung mengalir ke arah Sungai Ciliwung. Saluran ini mengalirkan air dari permukiman ke sungai melalui tapak. Solusinya dibutuhkan pengelolaan saluran pembuangan limbah dengan penempatan yang sesuai dan terintegrasi dengan Instalasi Pengelolaan Air Limbah (IPAL) (Gambar 7).

\section{Biofisik}

Data biofisik (flora) yang terdapat di sempadan Babakan Pasar sangat bervariasi baik tanaman tahunan maupun musiman. Beberapa jenis flora yaitu Markisa (Passiflora edulis), Jambu biji (Psidium guajava), Ara (Ficus racemosa L.), Mahoni (Swietenia mahagoni (L.) Jacq, Pisang (Musa paradisiaca), Talas (Colocasia esculenta L.), Kersen (Muntingia calabura), Pandan (Pandanus amaryllifolius).

\section{Konsep Lanskap Ekoriparian}

Lokasi perencanaan terletak berhadapan dengan sebuah kampung, yaitu Pulo Geulis, adalah nama sebuah pulau kecil yang terletak di tengah Sungai Ciliwung, Kelurahan Babakan Pasar, Kecamatan Bogor Tengah. Pulo Geulis telah ada sekitar tahun 1700-an, lokasi ini memiliki beragam nilai sejarah dan kebudayaan, terlihat dari salah satu peninggalan yaitu Vihara Maha Brahma. Bangunan ini diperkirakan dibangun pada tahun 1720 -an atau pada sekitar abad ke 18 dan diyakini sebagai klenteng tertua yang ada di Kota Bogor (Kurnadi, 2009).

Bentuk bangunan rumah warga di sekitar lokasi ini juga masih sangat terjaga keasliannya, lokasi ini sangat kental dengan nilai-nilai pluralisme dari suku, budaya, dan agama, didominasi oleh $60 \%$ etnis Sunda, 30\% etnis Tionghoa dan $10 \%$ etnis lainnya, warga yang berdiam di kelurahan ini hidup berdampingan dengan damai (Prihabsari, 2017).

Berada pada lokasi dengan nilai prularisme yang cukup tinggi, konsep ruang budaya ekoriparian Babakan Pasar akan menggabungkan dari kedua etnis Sunda dan Tionghoa. Konsep ini diimplementasikan dalam bentuk penggunaan warna, pemilihan vegetasi dan bentuk bangunan lanskap yang dapat menampung berbagai kegiatan yang ada di lokasi ini (Gambar 8). 


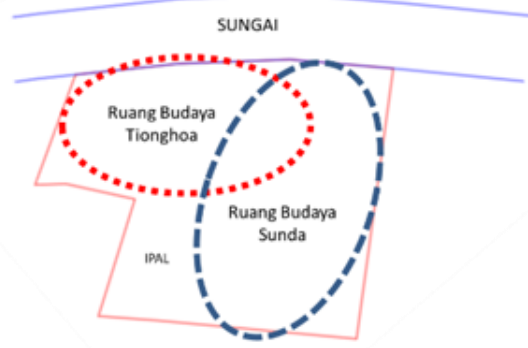

Gambar 8. Konsep Ruang Budaya Ekoriparian Babakan Pasar

Dalam perencanaan lankap ekoriparian Babakan Pasar digunakan pendekatan yang akan dijadikan sebagai konsep dasar desain sebagai berikut:

1. Menjaga keharmonisan hidup antara manusia, alam dan budaya melalui desain lanksap ekoriparian yang alami dan tertata.

2. Meciptakan desain tata hijau yang dapat meningkatkan nilai keindahan dan konservasi kawasan ekoriparian, serta memberikan rasa nyaman dan aman bagi masyarakat sekitarnya

3. Mengembangkan kawasan sebagai ruang terbuka hijau (ruang publik) berbasis kawasan rekreasi, edukasi yang dapat menampung berbagai kegiatan yang ada di dalam tapak.

Daerah Aliran Sungai (DAS) merupakan suatu sistem kompleks yang disusun dari tiga sistem, yaitu sistem fisik (physical system), sistem biologis (biological system) dan sistem manusia (human system) yang satu sama lain saling terkait dan saling berinteraksi (Susetyaningsih, 2012). Berada pada lokasi permukiman padat penduduk dan tinggi aktivitas diperlukan suatu konsep perencanaan yang dapat menyelaraskan kegiatan manusia dan alam, penerapan konsep ekoriparian diterapkan sebagai konsep dasar perencanaan, ekoriparian sebagai suatu konsep penataan sempadan sungai yang berfungsi sebagai restorasi dan konservasi area sungai, konsep ini memperhatikan tiap aspek lingkungan, sosial masyarakat dan ekonomi yang saling terintegrasi. Dalam konsep ini, terdapat beberapa syarat yang menjadi substansi utama dalam pembangunan ekoriparian, seperti adanya sistem pengolahan limbah (IPAL), RTH sebagai sarana sosial masyarakat, dan fungsi agroforestri, beberapa fungsi di atas disesuaikan dengan kondisi eksisting sempadan sungai yang akan direncanakan (Gambar 9).

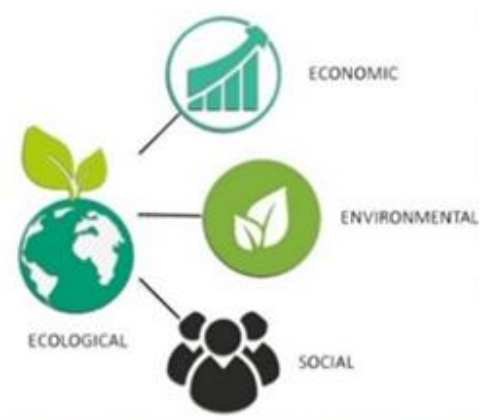

Gambar 9. Konsep Ekoriparian

Penataan ekoriparian Babakan Pasar mengarah kepada kebijakan "front view", yang dikenal dengan istilah waterfront (Gambar 10). Kebijakan ini berarti menjadikan sungai sebagai wilayah depan bagi pembangunan kawasan. Konsep ini dikembangkan dengan tujuan agar masyarakat dapat melihat fungsi sumber daya air sebagai sesuatu yang selain bermanfaat, tetapi juga menarik dipandang (Seftyono, 2012). Aspek yang dapat menunjang keberhasilan pengembangan kawasan waterfront pada segmen pengembangan, adalah kualitas lingkungan, teknologi, dan partisipasi masyarakat. Keberadaan bangunan sekitar tapak dapat mengadopsi konsep ini, setiap aktivitas yang berada di sekitar sempadan juga harus mendukung fungsi utama sempadan sungai, baik dari penataan vegetasi, pemilihan material, hingga aktivitas pengguna yang berkunjung ke dalam tapak.

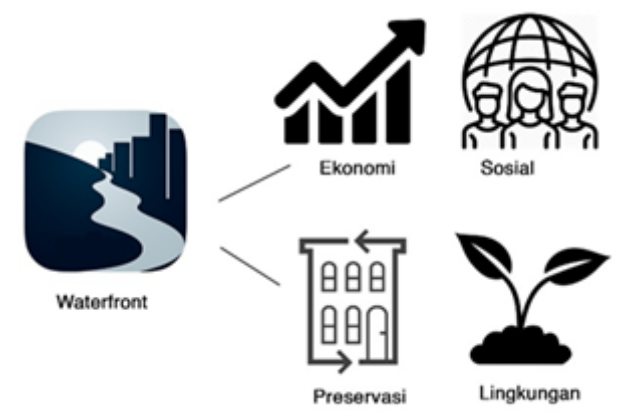

Gambar 10. Konsep Waterfront

\section{Pengembangan Konsep Perancangan}

\section{A. Zonasi Kawasan Ekoriparian Babakan Pasar}

Berdasarkan hasil analisis pada lokasi sempadan sungai Babakan Pasar, konsep perencanaan lanskap ekoriparian dibagi dalam 3 zona yaitu zona penyangga, pengembangan dan IPAL. Zona pengembangan terdiri dari ruang penerima dan ruang interaksi, zona penyangga terdiri dari ruang agroforestri dan pembibitan, zona IPAL terdiri dari fasilitas pengolahan air limbah, node merupakan ruang peralihan antara satu ruang dengan lainnya, berupa fasilitas plaza (Gambar 11).

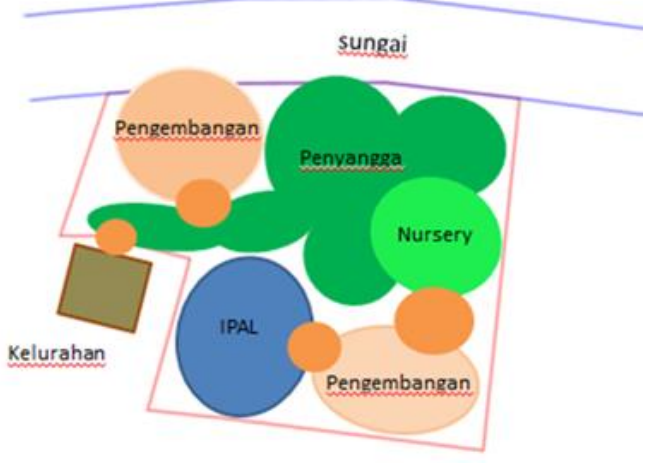

Gambar 11. Zonasi Ekoriparian Babakan Pasar

1) Zona Penyangga

Dilakukan optimalisasi fungsi sempadan sungai melalui penataan lanskap ekoriparian dengan fasilitas penunjang seperti kegiatan sederhana berbasis alam yang tidak mengubah kondisi alami sempadan sungai dan dapat meningkatkan ekonomi masyarakat sekitar.

2) Zona Pengembangan

Pada zona pengembangan bentuk penataan lanskap sempadan sungai sebagai wadah interaksi sosial masyarakat, penataan vegetasi dan bangunan lanskap tetap memperhatikan aspek lingkungan sempadan sungai. 


\section{B. Konsep Visual}

Konsep visual dibagi menjadi 2 yaitu pemandangan ke dalam tapak dari arah luar ke dalam tapak dan pemandangan dalam tapak mengarah ke air (sungai). Kualitas visual dapat ditingkatkan dengan penempatan ruang terbuka (plaza) pada masing-masing area peralihan untuk mengarahkan pandangan pada fasilitas dan tata hijau yang ada di dalam tapak dan mengarahkan pandangan ke arah air atau sungai (Gambar 12).

\section{Konsep Vegetasi}

Seperti diungkapkan oleh Forman dan Gordon (1983), bahwa sempadan sungai pada dasarnya merupakan habitat dari vegetasi riparian. Dengan demikian peranan fungsi bantaran sungai bukan terbatas pada peranan fungsi fisiknya, namun demikian peranan fungsi vegetasi riparian juga memberikan informasi yang cukup berperan dalam jasa biologis dan hidrologisnya.

Kriteria pemilihan vegetasi untuk sempadan sungai

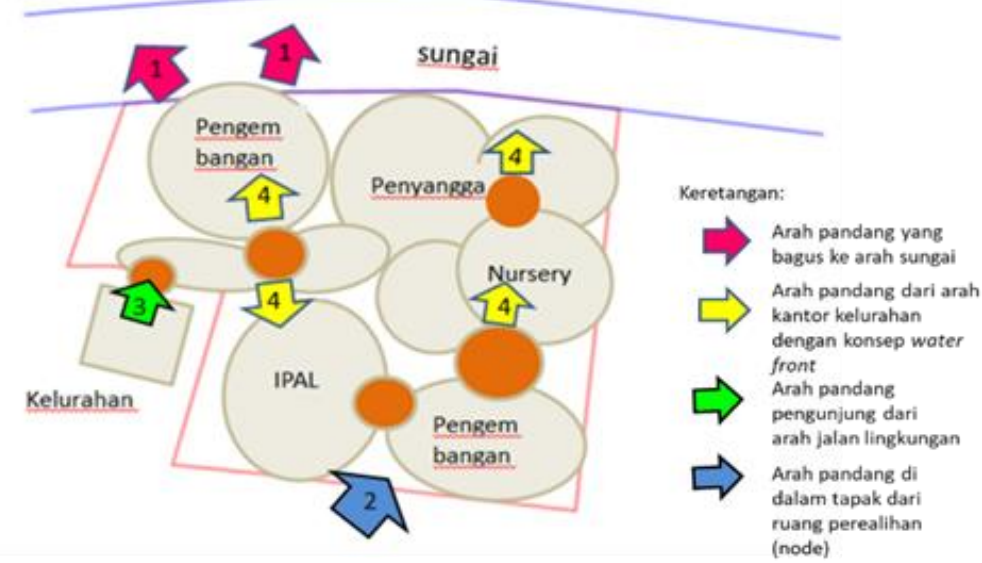

Gambar 12. Konsep Visual Ekoriparian Babakan Pasar

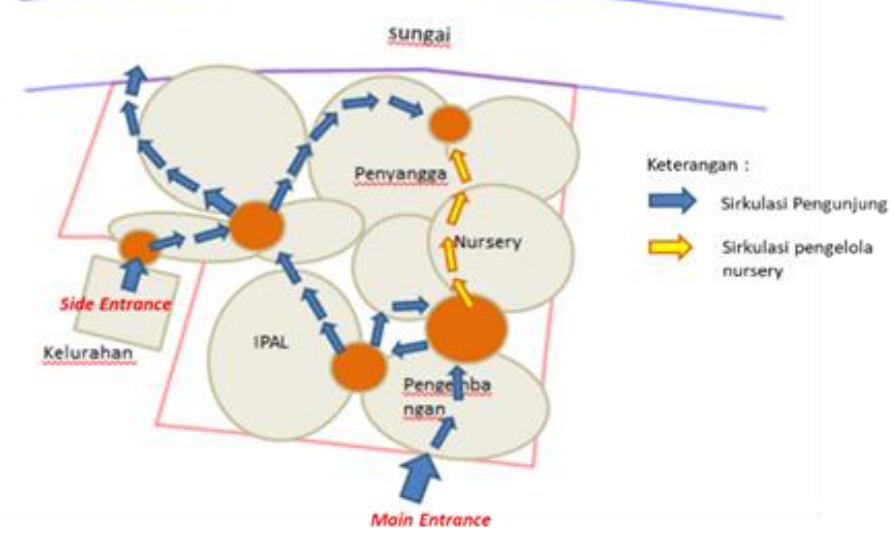

Gambar 13. Konsep Sirkulasi dan Akses Masuk Ekoriparian Babakan Pasar

\section{Konsep Sirkulasi dan Akses Masuk (Entrance)}

Pola sirkulasi pada sempadan sungai Babakan Pasar menggunakan pola campuran dengan menempatkan jalan setapak sebagai jalur pejalan kaki dan akses yang menghubungkan antar ruang dengan node sebagai penghubung ruang. Sirkulasi pengunjung diperuntukkan untuk pengguna tapak secara umum, sedangkan sirkulasi pengelola hanya diperuntukkan kusus untuk kegiatan pengelolaan nursery (pembibitan). Penataan pola sirkulasi dengan material alami seperti penggunaan batu kali dan bata expose dapat meningkatkan nilai visual dan kebersihan kawasan. Penetapan pintu masuk (entrance) dilakukan berdasarkan analisis yang telah dilakukan, pintu masuk utama (main entrance) diletakkan pada bagian timur tapak agar mudah menjangkau tiap ruang yang ada dalam tapak, usulan untuk menambahkan side entrance melalui kantor kelurahan dilakukan agar bagian ini dapat menjadi satu kesatuan, kantor kelurahan menjadikan tapak ekoriparian menjadi bagian depan bagi lingkungan sekitar (mengadopsi konsep front view), selain itu juga dapat memudahkan kegiatan pemeliharaan ekoriparian (Gambar 13). menurut PERMEN PU No: 05/PRT/M/2008 adalah sebagai berikut:

1) sistem perakaran yang kuat, sehingga mampu menahan pergeseran tanah;

2) tumbuh baik pada tanah padat;

3) sistem perakaran masuk ke dalam tanah, tidak merusak konstruksi dan bangunan;

4) kecepatan tumbuh bervariasi;

5) tahan terhadap hama dan penyakit tanaman;

6) jarak tanam setengah rapat sampai rapat $90 \%$ dari luas area, harus dihijaukan;

7) tajuk cukup rindang dan kompak, tetapi tidak terlalu gelap;

8) berupa tanaman lokal dan tanaman budidaya;

9) dominasi tanaman tahunan;

10) sedapat mungkin merupakan tanaman yang mengundang burung.

Keberadaan vegetasi di sempadan sungi atau riparian memiliki fungsi hidraulik dan ekologi terhadap lingkungan sungai. Pola pembagian zonasi lingkungan 
alami pada zona penyangga dan pengembangan terdiri dari riparian zone. Jenis tanaman tersebut terdiri dari groundcover, perdu, semak dan pohon. Diantaranya adalah nangka (Artocarpus heterophyllus), petai cina (Leucaena leucocephala), jambu biji (Psidium guajava), durian (Durio zibethinus), alpukat (Persea americana), waru (Hibiscus tiliaceus), cempaka (Magnolia champaca), bambu (Bambusa vulgaris), kemiri (Aleuritas moluccana), flamboyan (Delonix regia), kenikir (Cosmos caudatus). Berdasarkan hasil studi yang dilakukannya Budinetro dalam Maryono (2008), terdapat tiga jenis tumbuhan yang dapat digunakan untuk menahan tebing, yaitu rumput vetiver atau rumput akar wangi (Vetiveria zizanioides), karangkungan (Ipomoea carnea) dan bambu (Bambusa sp.). Pada zona penyangga terdapat vegetasi tanaman pertanian, diantaranya tomat (Solanum lycopersicum), bawang merah (Allium cepa), cabai (Capsicum frutescens), selada (Lactuca sativa), pakcoy (Brassica rapa) (Gambar 14).

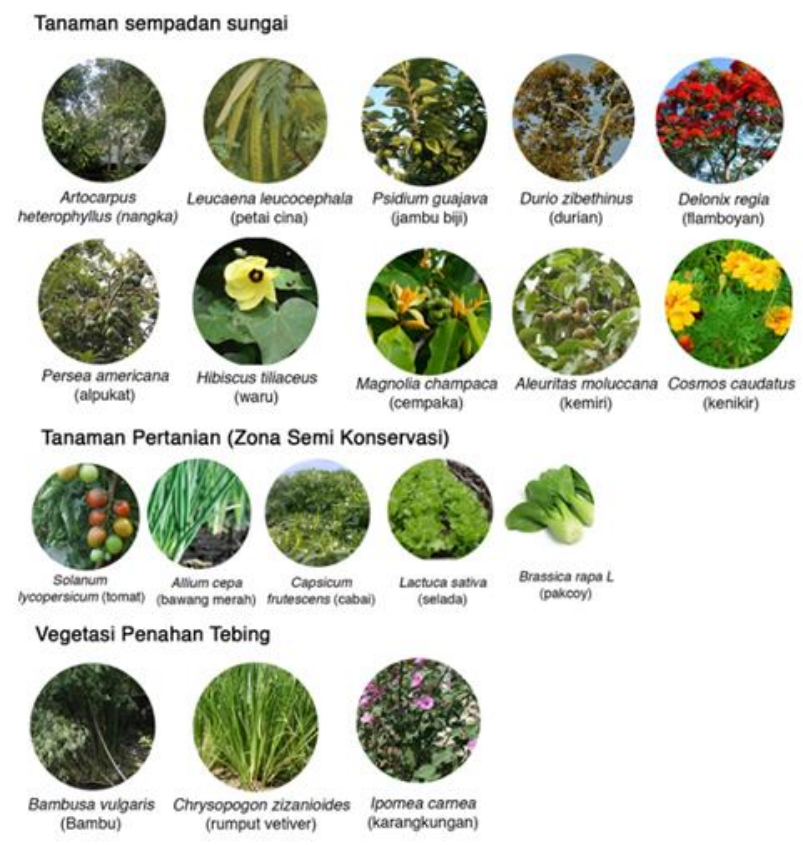

Gambar 14. Pilihan Vegetasi yang Sesuai di Sempadan Sungai

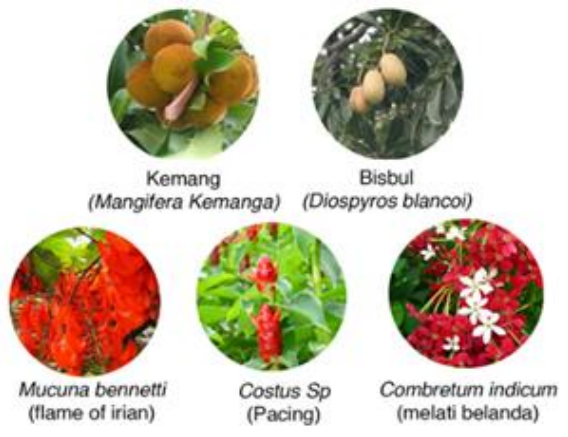

Gambar 15. Vegetasi Identitas

Vegetasi eksisting perlu dipertahankan dan ditingkatkan keadaannya, vegetasi khas Kota Bogor digunakan untuk memunculkan identitas tapak, diantaranya adalah tanaman kemang (Mangifera kemanga), bisbul (Diospyros blancoi), selain itu juga digunakan tanaman fungsi estetis yang berwarna merah untuk menunjukkan identitas Tionghoa, diantaranya adalah flame of irian (Mucuna bennetti), pacing (Costus sp.), dan melati belanda (Combretum indicum) (Gambar 15).
Pada zona IPAL, dapat diletakkan tanaman air, menurut Baroroh dan Irawanto (2016), untuk mengurangi limbah domestik, digunakan tanaman air seperti Echinodorus radicans, Sagittaria lancifolia, Ludwigia adcendens, Thalia geniculate, Typha angusifolia, Cyperus sp., Oryza minuta. Vegetasi agroforestri dan konsep urban farming diterapkan untuk meningkatkan kualitas lingkungan dan ekonomi dan edukasi masyarakat sekitar.

\section{Konsep Lanskap Agroforestri}

Konsep lanskap agroforestri ekoriparian pada riparian Sungai Ciliwung Babakan Pasar penting dikembangkan untuk tujuan konservasi, meningkatkan nilai estetika dan nilai ekonomi lahan sempadan sungai. Pengelolaan sempadan sungai merupakan salah satu aspek penting dalam menentukan pertumbuhan tanaman pada lanskap agroforestri. Pengelolaan sempadan dalam konteks ini lebih menitikberatkan pada kegiatan pemeliharaan tanaman agroforestri, baik itu tanaman pokok (pepohonan) maupun kombinasi tanaman sela (tanaman semusim).

Agroforestri merupakan kombinasi dari beberapa komponen vegetasi, aspek terpenting dalam komponen vegetasi adalah susunan tajuk dari sistem agroforestri yang berlapis-lapis, jenis pohon dan tanaman bawah. Komposisi vegetasi ini terkait dengan peran dan fungsi terhadap evapotranspirasi, intersepsi hujan, dan iklim mikro. Peran tersebut menyebabkan sistem agroforestri memiliki kemiripan dengan hutan (Hairiah, Sardjono, \& Sabarnurdin, 2003) dan dapat dikelola dengan konsep lanskap agroforestri (Arifin et al., 2009)). Sistem agroforesti mampu mempertahankan produktivitas lahan, dan sekaligus memberikan perlindungan terhadap fungsi hidrologi DAS. Hubungan antara pengelolaan DAS yang berkelanjutan (lestari) dengan fungsi hidrologi dan agroforestri, disajikan pada Gambar 16.

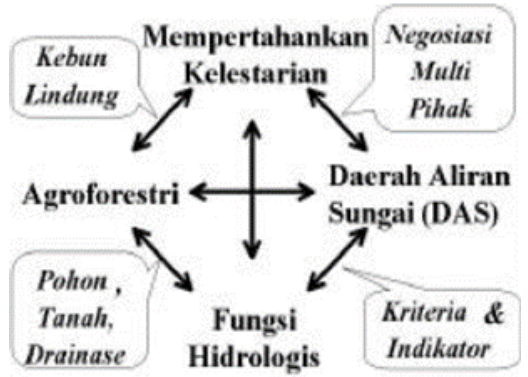

Gambar 16. Hubungan antara pengelolaan DAS berkelanjutan dengan fungsi hidrologi dan agroforestri.

(Van Noordwijk et al. 2004)

Secara ringkas, Sabarnurdin (2004) menyebutkan beberapa manfaat lingkungan yang dapat diperoleh dari sistem agroforestri:

1) mengurangi tekanan terhadap hutan, sehingga fungsi kawasan hutan tidak terganggu (tata air, keanekaragaman hayati);

2) lebih efisien dalam recycling unsur hara melalui pohon berakar dalam di lokasi wilayah DAS;

3) perlindungan yang lebih baik terhadap sistem ekologi daerah hulu DAS;

4) mengurangi aliran permukaan, pencucian hara dan erosi tanah;

5) memperbaiki iklim mikro, mengurangi suhu permukaan tanah, mengurangi evapotranspirasi 
karena kombinasi mulsa dari tanaman setahun atau tanaman semusim dan naungan pohon;

Konsep tata hijau pada ekoriparian Babakan Pasar dapat dilihat pada Gambar 17

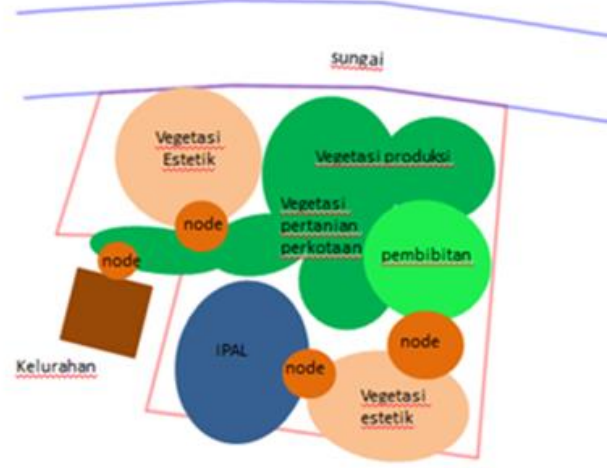

Gambar 17. Konsep Vegetasi Ekoriparian Babakan Pasar (Sumber: Hasil Analisis, 2019)

\section{E. Konsep Bentuk}

Keadaan lokasi ekoriparian Babakan Pasar sangat kental dengan nilai-nilai pluralisme, konsep bentuk yang digunakan adalah perpaduan antara etnis Sunda dan Tionghoa. Kujang merupakan salah satu senjata khas Jawa Barat, tepatnya di Pasundan (Tatar Sunda) yang menjadi ikon Kota Bogor. Kujang sangat identik dengan Sunda Pajajaran, karena merupakan salah satu aspek identitas eksistensi budaya Sunda. Penggunaan warna-warna yang khas warna pada arsitektur Tionghoa memiliki arti/makna simbolik. Warna-warna tertentu pada umumnya diberikan pada elemen-elemen tertentu pada bangunan, karena warna merupakan salah satu penerapan dari aspek religi/kepercayaan masyarakat Tionghoa. Pendekatan bentuk ini bertujuan agar tercipta keterhubungan bentuk arsitektural Sunda dan Tionghoa, yang akan diimplementasikan secara tematik pada elemen lanskap ekoriparian Babakan Pasar (Gambar 18).
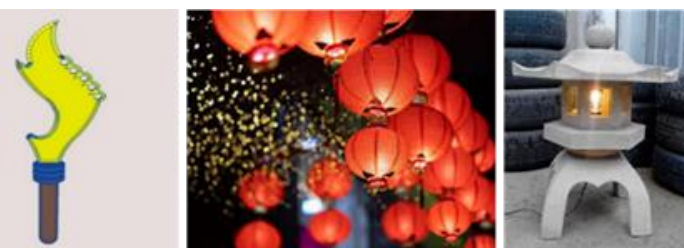

Gambar 18. Konsep Bentuk Ekoriparian Babakan Pasar (Sumber: google.com)
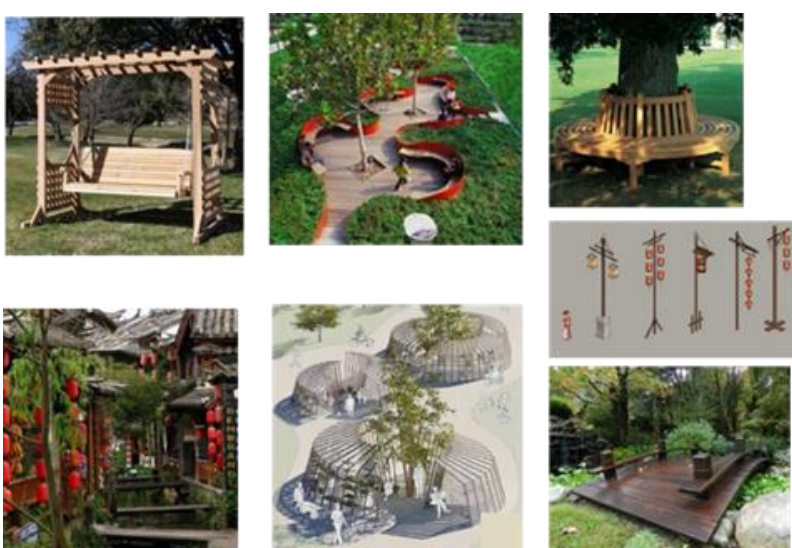

Gambar 19. Referensi Elemen Lanskap Ekoriparian Babakan Pasar (Sumber: google.com)
Desain elemen lanskap pada lokasi ini juga menggunakan komposisi konsep di atas, diimplementasikan dalam bentuk tempat sampah, lampu taman, plaza, dan lainnya. Material yang dipilih menggunakan bahan yang ramah lingkungan untuk meningkatkan kesan alami dari suatu sempadan sungai (Gambar 19).

\section{Desain Ekoriparian Babakan Pasar}

\section{A. Siteplan Ekoriparian Babakan Pasar}

Konsep-konsep yang telah disusun, dituangkan menjadi desain dalam bentuk dua dimensi, yang memperlihatkan desain keseluruhan tapak serta peletakan fasilitas softscape maupun hardscape (Gambar 20).

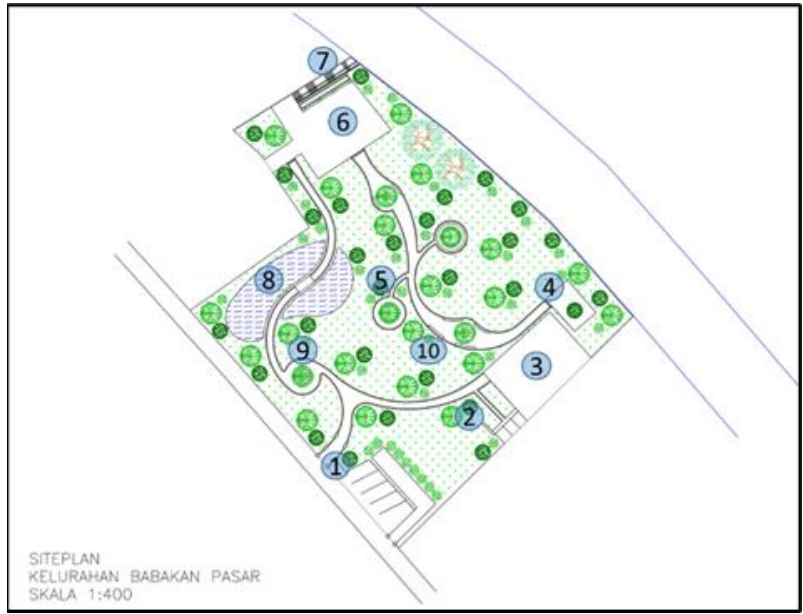

Gambar 20. Siteplan Ekoriparian Babakan Pasar

Keterangan:

1) Pintu masuk, parkiran dan pergola pada koridor pejalan kaki

2) Gudang dan toilet

3) Area Pembibitan (nursery)

4) Area duduk

5) Sarana pertanian perkotaan

6) Plaza sebagai sarana olahraga dan edukasi

7) Tangga menuju rekreasi air

8) Area IPAL dengan elemen jembatan kecil sebagai penguat estetika

9) Ruang peralihan dengan fasilitas tempat duduk

10) Ruang peralihan untuk fungsi interaksi dengan fasilitas tempat duduk

\section{B. Visualisasi Ekoriparian Babakan Pasar}

Tampak atas desain taman Ekoriparian Babakan Pasar dalam bentuk tiga dimensi dapat dilihat pada Gambar 21. Area penerimaan terdiri dari fasilitas gapura utama yang menggunakan aksen Tionghoa dan gapura akses motor menggunakan aksen Jawa Barat yaitu kujang, terdapat pula lahan parkir untuk mobil dan motor, serta pergola yang ditumbuhi tanaman merambat (Gambar 22).

Pada zona penyangga terdapat area pembibitan (nursery) dan sarana pertanian perkotaan dengan (Gambar 23). Untuk menikmati lingkungan sekitar disediakan beberapa fasilitas tempat duduk pada ruang peralihan (Gambar 24). Terdapat sebuah plaza eksisting yang digunakan sebagai sarana olahraga dan edukasi budaya, elemen lanskap pada area ini di desain menggunakan aksen Tionghoa dan corak bunga bangkai untuk menunjukkan identitas tapak yang dekat dengan Kebun Raya Bogor, terdapat juga 


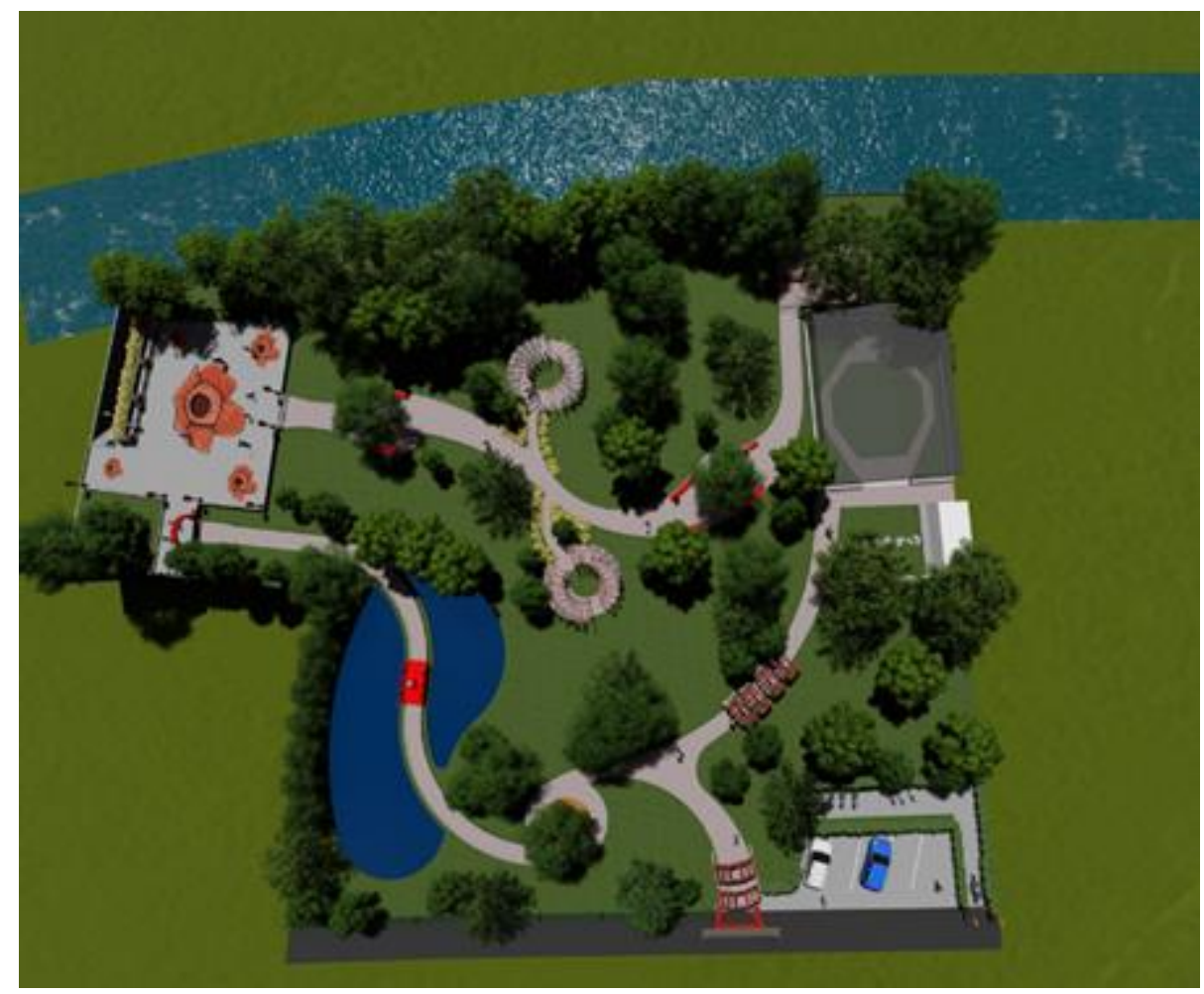

Gambar 21. Model 3D Ekoriparian Babakan Pasar
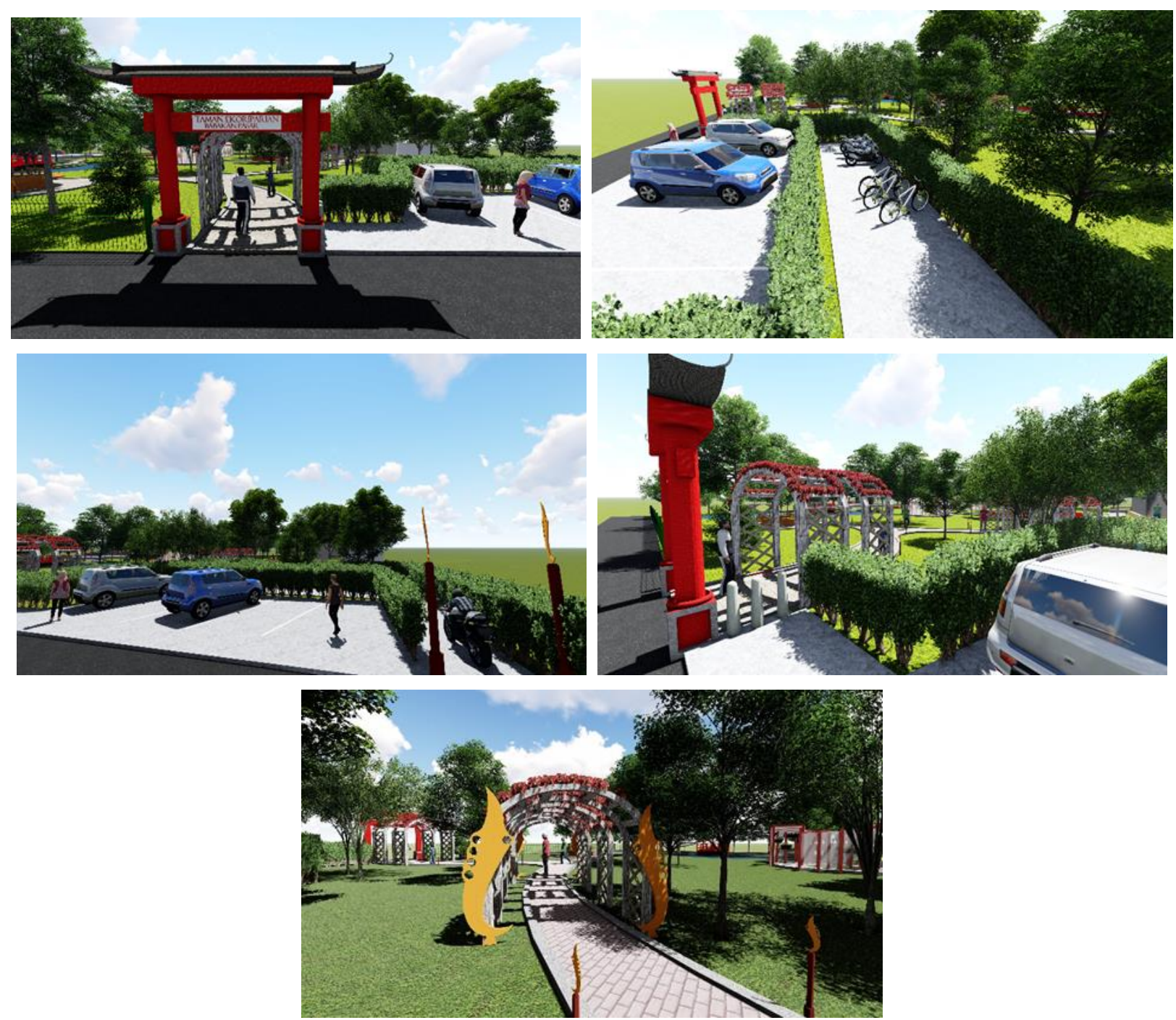

Gambar 22. Area Penerima Ekoriparian Babakan Pasar 


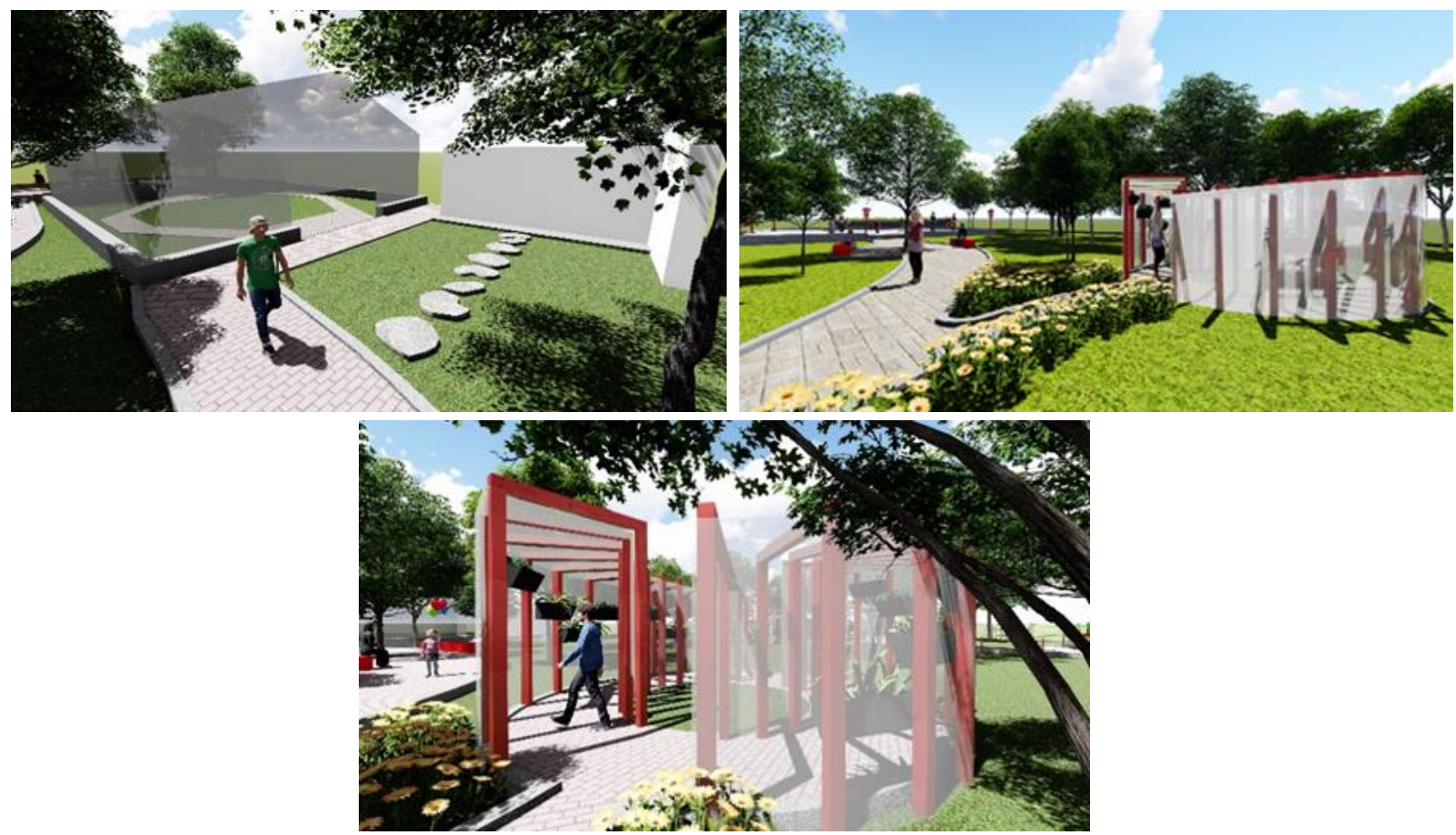

Gambar 23. Nursery dan Sarana Pertanian Perkotaan

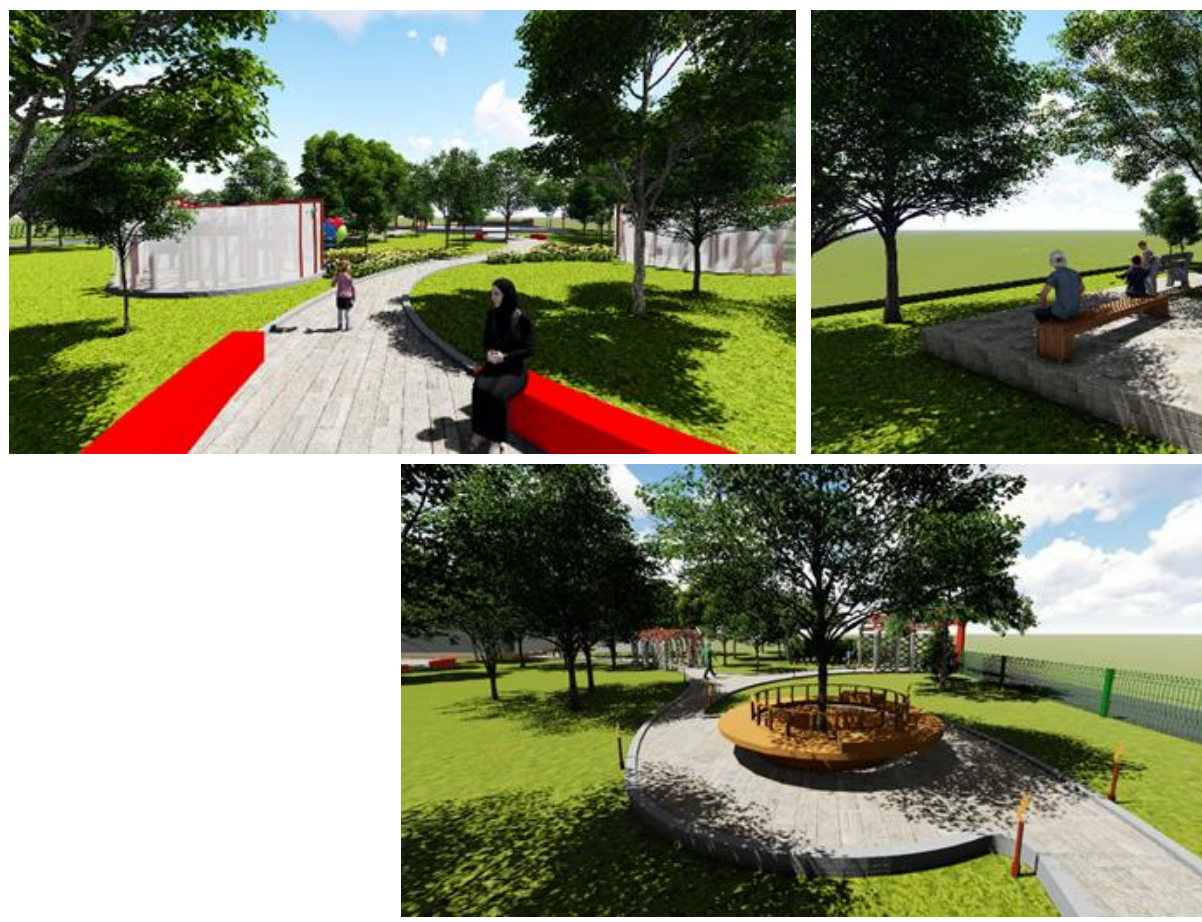

Gambar 24. Area Duduk

tangga yang menjadi akses menuju sungai (Gambar 25). Pada area IPAL terdapat kolam dan elemen jembatan kecil untuk menambah nilai estetik kawasan (Gambar 26).

\section{SIMPULAN}

Ekoriparian merupakan pemanfaatan sempadan sungai untuk menjadi pusat wisata edukasi lingkungan dengan tidak mengganggu ekosistem yang ada dan dalam pengelolaannya melibatkan peran serta masyarakat. Dengan pelibatan masyarakat ini diharapkan akan merubah pola pikir masyarakat yang semula menjadikan sungai sebagai tempat untuk membuang sampah dan air limbah, sekarang masyarakat ikut menjaga sungai (waterfront), sehingga tujuan perbaikan kualitas air sungai akan tercapai. Melalui ekoriparian ini diharapkan dapat memperbaiki kualitas air sungai dengan menurunkan beban pencemaran melalui Instalasi Pengolahan Air Limbah (IPAL) serta berbagai fasilitas lain untuk menunjang perubahan pola pikir masyarakat mengenai kelestarian sungai yang dilakukan dengan perencanaan lanskap yang benar.

Berada di area padat penduduk dengan nilai pluralisme yang tinggi, desain Taman Ekoriparian Babakan Pasar menggabungkan konsep budaya Sunda dan Tionghoa yang dituangkan dalam bentuk desain elemen lanskap dan pilihan warna. Zonasi tapak terbagi menjadi tiga yaitu zona pengembangan, penyangga dan IPAL, masingmasing ruang memiliki fasilitas dan fungsi yang berbeda, kegiatan pada zona pengembangan merupakan rekreasi 

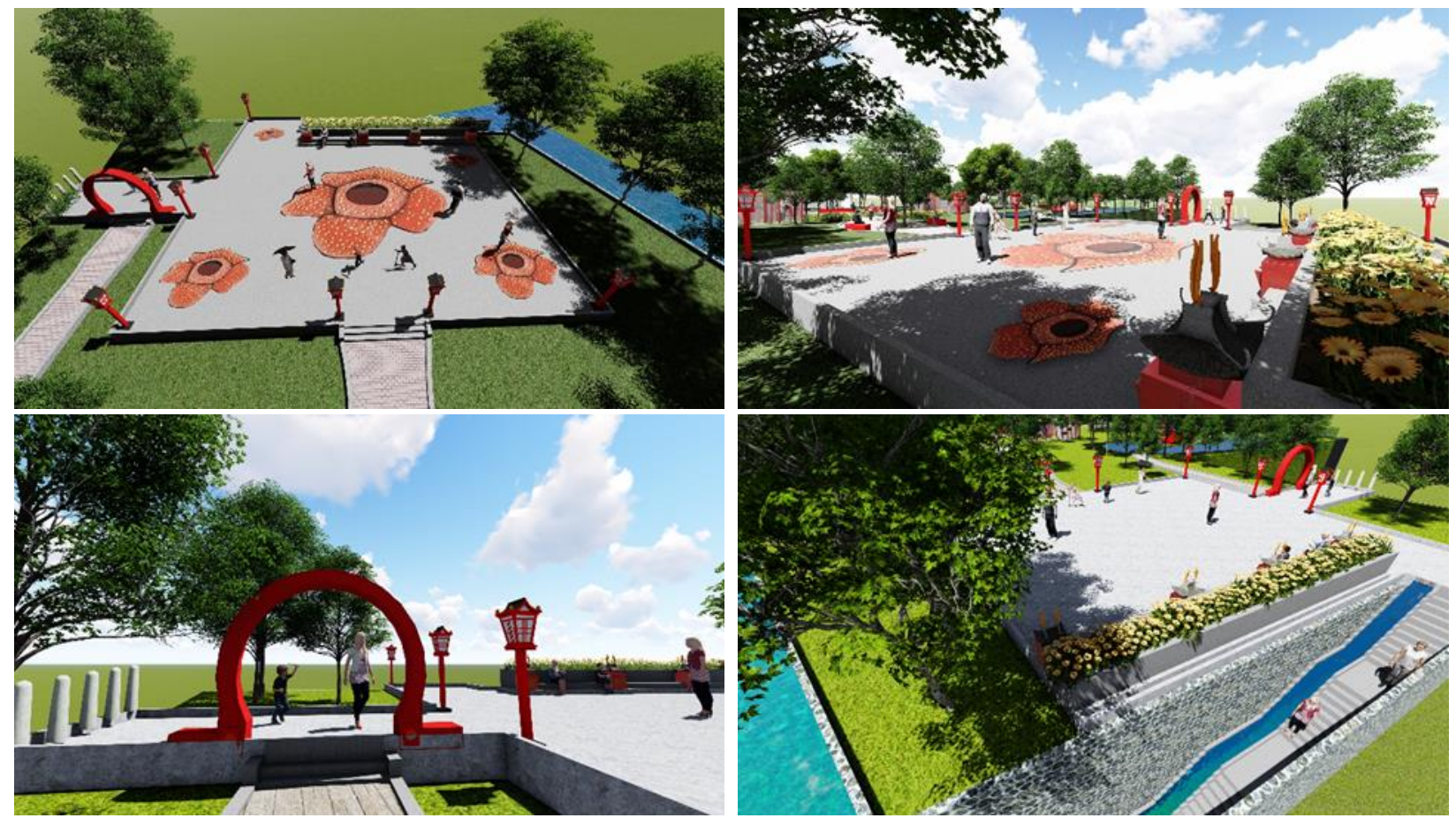

Gambar 25. Plaza Sarana Olahraga dan Edukasi Budaya

sederhana berbasis alam yang tidak mengubah kondisi alami tapak sebagai sempadan sungai. Vegetasi yang digunakan adalah vegetasi khas sempadan dan vegetasi penguat identitas kawasan, selain itu konsep agroforestri dan pertanian perkotaan juga diletakkan pada zona penyangga yang dapat dikelola oleh masyarakat sekitar.

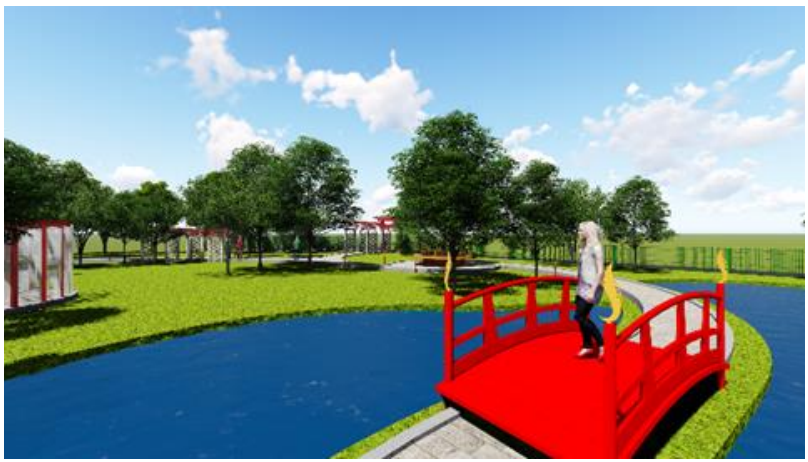

Gambar 26. Area IPAL

\section{DAFTAR PUSTAKA}

[KLHK] Kementerian Lingkungan Hidup dan Kehutanan: Biro Perencanaan. 2020. Laporan Kinerja 2019. https:/ / bit.ly/LKJ KLHK 2019

Arifin, H.S., Wulandari, C., Pramukanto, Q., Kaswanto, R.L. 2009. Analisis Lanskap Agroforestri: Konsep, Metode, dan Pengelolaan Agroforestri Skala Lanskap. IPB Press. Bogor, Indonesia.

Baroroh, F., Irawanto, R. 2016. Seleksi Tumbuhan Akuatik Berpotensi Dalam Fitoremediasi Air Limbah Domestik di Kebun Raya Purwodadi. Malang: Prosiding Seminar Nasional Biologi. Universitas Negeri Malang.

Forman, R., Gordon, M. 1983. Lansdcape Ecology. New York: John Wiley \& Son.

Gold, S.M. 1980. Recreation Planning and Design. New York: McGraw-Hill Book Co. 568 p.
Hairiah K, Sardjono MA, Sabarnurdin S. 2003. Pengantar Agroforestri. Bogor: ICRAF.

Kurnadi, K.P. 2009. Studi Lanskap Bersejarah Kawasan Pecinan Suryakencana, Bogor. [skripsi]. Bogor: Institut Pertanian Bogor.

Menteri Pekerjaan Umum 2008. Peraturan Menteri Pekerjaan Umum Nomor: 05/PRT/M/2008 tentang Peroman dan Pemanfaatan Ruang Terbuka Hijau di Kawasan Perkotaan.

Prihabsari, A.K. 2017. Desain Lanskap Kampung Wisata Pulo Geulis Berbasis Preferensi Masyarakat. [skripsi]. Bogor: Institut Pertanian Bogor.

Sabarnudin, M.S. 2004. Agroforestry: Konsep, Prospek dan Tantangan. Presentasi Workshop Agroforestry. Yogyakarta: Fakultas Kehutanan Universitas Gadjah Mada.

Seftyono, C. 2012. Pembangunan berbasis Waterfront dan Transformasi Konflik di Bantaran Sungai: Sebuah Pemikiran Awal. Jurnal Ilmu Sosial dan Ilmu Politik. 16(1): 75-83

Soewandita, H., Sudiana, N. 2010. Studi Dinamika Kualitas Air DAS Ciliwung. Jurnal Air Indonesia, 6(1), 24-33.

Susetyaningsih, A. 2012. Pengaturan Penggunaan Lahan di Daerah Hulu DAS Cimanuk Sebagai Upaya Optimalisasi Pemanfaatan Sumber daya Air. Jurnal Konstruksi STTGarut. 10(1).

Van Noordwijk, M., Agus, F., Suprayogo, D., Hairiah, K., Pasya, G., Verbist, B., 2004. Peranan agroforestri dalam mempertahankan fungsi hidrologi daerah aliran sungai (DAS). Jurnal AGRIVITA. (26):1.

Yudo, S., Said, N.I. 2018. Status Kualitas Air Sungai Ciliwung di Wilayah DKI Jakarta. Studi Kasus: Pemasangan Stasiun Online monitoring Kualitas Air di Segmen Kelapa Dua - Masjid Istiqlal. Jurnal Teknologi Lingkungan, 19(1), 13-22. 